\title{
OPENING NEW INSTITUTIONAL SPACES FOR GRAPPLING WITH UNCERTAINTY: A CONSTRUCTIVIST PERSPECTIVE
}

\author{
Dr Ronlyn Duncan \\ Lecturer in Water Management \\ Department of Environmental Management \\ Faculty of Environment, Society and Design \\ Lincoln University \\ Christchurch \\ Ronlyn.Duncan@lincoln.ac.nz \\ Tel: +64 34230427 \\ Published in Environmental Impact Assessment Review 38 (2013): 151-154. \\ Final version available from http://www.sciencedirect.com/
}

\begin{abstract}
In the context of an increasing reliance on predictive computer simulation models to calculate potential project impacts, it has become common practice in impact assessment (IA) to call on proponents to disclose uncertainties in assumptions and conclusions assembled in support of a development project. Understandably, it is assumed that such disclosures lead to greater scrutiny and better policy decisions. This paper questions this assumption. Drawing on constructivist theories of knowledge and an analysis of the role of narratives in managing uncertainty, I argue that the disclosure of uncertainty can obscure as much as it reveals about the impacts of a development project. It is proposed that the opening up of institutional spaces that can facilitate the negotiation and deliberation of foundational assumptions and parameters that feed into predictive models could engender greater legitimacy and credibility for IA outcomes.
\end{abstract}

Keywords: predictive simulation modelling, uncertainty, collaborative knowledgemaking, narrative analysis 


\section{OPENING NEW INSTITUTIONAL SPACES FOR GRAPPLING WITH UNCERTAINTY: A CONSTRUCTIVIST PERSPECTIVE}

\section{Introduction}

It has been recognized since the 1980s that uncertainty pervades impact assessment (IA) (Hellstrom and Jacob 1996). As such, we have to live with uncertainty and learn to manage it (Glasson et al. 2005). How is uncertainty managed in practice? The United Kingdom's Institute of Environmental Management and Assessment (IEMA) recommends disclosure (see also Glasson et al. 2005). Clause 6 of its Practitioner's Code of Practice states:

Ensure that where incomplete baseline data is used in an assessment and/or uncertainty exists in the predictions or results of an assessment this is so indicated in [the] Environmental Impact Statement or Impact Assessment Report (IEMA no date: $\mathrm{np}$ ).

Here uncertainty is rendered manageable by its requisite disclosure. Understandably, it is assumed that such disclosures lead to greater scrutiny of development projects and better policy decisions. Such was the expectation of an independent statutory body overseeing the integrated impact assessment of the major energy infrastructure project in Australia known as Basslink - a 360 kilometre undersea electricity cable that now links the Australian mainland to its southern island state of Tasmania. The project proponents were directed to be explicit about what was uncertain and contingent in their methodologies and conclusions in respect of the project:

Assumptions, simplifications and scientific judgments should be stated clearly and the nature and magnitude of uncertainties should be clearly defined. Where relevant, the choice of a particular methodology over alternative methodologies should be explained (JAP 2000: 41).

Embodying the disclosure remedy, uncertainty here is assumed readily identifiable, quantifiable and communicable. While it is acknowledged that the recognition of uncertainty in these terms is necessary, I will argue that it is not sufficient. In my view, a 
reliance on supposedly objective disclosure is unreliable in the predictive model context in which IA is now embedded (Duncan 2008). Indeed, I would argue that a reliance on disclosure runs the risk of reductionism and leaves unexamined the social-interactive aspects of uncertainty.

\section{Analytic Framework}

\subsection{A constructivist perspective and the challenging IA predictive model context}

Research from the field of science studies shows that perceptions of uncertainty can vary with their distance from sites of knowledge production and actors’ institutional locations across the domains of science and policy (Collins 1988, MacKenzie 1990; see also Jasanoff and Wynne 1998, Lahsen 2005, Shackley and Wynne 1995). Drawing on these constructivist theories of knowledge, in Duncan (2008) I examine the epistemic implications of what has become standard IA practice whereby proponents engage multiple firms of consultants from across the biophysical and social sciences that utilize a range of predictive models to develop what eventually becomes a unified integrated impact assessment statement. In this empirical study I illustrate how this knowledgemaking practice can both isolate from critique and perpetuate a proponent’s partisan worldview of what could or should transpire in the future if a project gains approval. I show how, when the conclusions derived from one predictive model are passed between consultant firms and run through subsequent predictive models, uncertainties and contingencies can be amplified by virtue of the proponent's knowledge production process that constitutes a knowledge producer simultaneously as a knowledge user. The outcome is that with each modelling iteration the links between model inputs and outputs and their concomitant uncertainties and contingencies are severed (see also Vaughan 1999). Consequently, possibilities for critique and disclosure are closed off: 
unless explicit clarifications are called for, what has become standard procedure would serve to isolate actors contributing to the development of an integrated impact statement. This isolation would diminish disclosure between collaborating consultants as well as to the impact statement audience, be they supporters, critics, regulators, assessors or decisionmakers. Therefore, reliability of the conclusions presented in impact statements would not be attributable to the rigorous challenge or peer review of a proponent's claims, but rather to 'imposed trust' between actors required to collaborate at the behest of a proponent (Duncan 2008: 63).

In this context, uncertainties and contingencies would not and could not be known by individual actors that are merely links in a chain.

\subsection{A discourse approach}

To further illustrate the inadequacy of a reliance on the disclosure of uncertainty in IA, I now turn to analyzing its social-interactive dimensions. Discourse is a conception of language as social practice (Wood and Kroger 2000). This means that not only is our world described by our talk, it is constituted in and by that talk. Burman and Parker (1993: 3) make the point that language also "constrains meaning” and that discourse analysis "offers a social account of subjectivity by attending to the linguistic resources by which the sociopolitical realm is produced and reproduced”. Hajer (1995: 44) defines discourse as "a specific ensemble of ideas, concepts, and categorizations that are produced, reproduced, and transformed in a particular set of practices and through which meaning is given to physical and social realities”. From a discursive perspective, a proponent's rendition of the disclosure of uncertainty can be conceptualized as a social-interactive knowledge-making outcome (Hajer 1995) rather than an inventory of objective assumptions and limitations.

\subsection{The role of stories in uncertainty disclosure}


Emery Roe, who has applied literary theory and sociolinguistics to policy-making (Hajer and Laws 2006: 260), advocates a focus in policy analysis on the stories people adopt, tell and perpetuate. Roe maintains that when it is not possible to identify an objective reality in policy debates that are mired in complexity, polarization and uncertainty, the analytical task becomes one of describing how actors are "certain of uncertainty" and how actors persuade others about certainty (1994: 110). Roe maintains that narratives are "the only things left to examine” in perplexing controversies (1994:

3), and that certainty can derive from and is mobilised by stories:

It is only when the reality being described is so uncertain ... that we must look to how the structural features of narratives enable their narrators to speak with such certainty about the policy relevance of what is so uncertain, without thereby being implicated in the uncertainty being described (Roe 1994: 112).

According to Roe, the analytical task is not to judge whether claims are true or not, or to delve too far into technical debates over ambiguities (or create them), but to understand how the ambiguities were managed and a consensus formed around what become final outcomes. Hajer and Laws (2006) identify a narrative analysis as a conceptual tool used by analysts "to capture how policy actors deal with ambiguity ... and explain how policy makers structure reality to gain a handle on practical questions”. These authors further argue that narrative analysts have "shown that storytelling is a principle way of ordering, of constructing shared meaning and organizational realities” (2006: 260 citing Boyce 1995). In other words, the stories actors or actor-collectives tell amongst themselves help them make sense of and reduce complexity and uncertainty. Is storytelling involved in the disclosure of uncertainty in IA? When one considers the complexity and expanse of the issues IA seeks to address and integrate, the numbers of actors involved, its interminably deficient knowledge base, the high stakes of its decisions, its lack of post-project verification and its reliance on increasingly complex 
predictive computer modelling to forecast an unknowable future; and given how foundational storytelling appears to be according to the above authors; arguably, it would be a surprise if this was not the case.

\section{A Narrative Analysis}

\subsection{Predictive models, baselines and uncertainties}

Revealing the social-interactive aspects of uncertainty, in particular, the stories people tell about uncertainty, highlights the inadequacy of a reliance on disclosure to manage uncertainty. Consider the Basslink project. The proponent's consultants' were required to predict and integrate the environmental, social and economic impacts of connecting a State-based hydro-electricity system and the running of its lakes and rivers to a predominantly coal-based national electricity market operating on the Australian mainland. To substantiate the hydro corporation proponent's claim that the anticipated change from historically low volume and stable hydro power station discharges to considerably higher and more variable discharges to meet national peak demand would not compromise the World Heritage values of Tasmania’s Gordon River, the proponent had scant baseline data. To make its case in accordance with the statutory requirements, the proponent's consultants had to use power station discharge data with its unavoidable gaps and conversion limitations to predict what might occur with Basslink. A predictive simulation model of the hydro-system was used. It had been developed several years earlier when moves were afoot to privatise Tasmania’s hydro-system. To integrate the financial aspects of the cable’s operations with potential environmental effects, a national electricity market trading module was incorporated into the hydrosystem model to simulate arbitrage transactions. Subsequently, the assembled baseline data without imports and exports across link and a simulation with them was passed to 
external environmental researchers to calculate environmental impacts of expected changes in power station discharges on the various aspects of river ecology (Duncan 2006). This meant that all of the environmental impact predictions were anchored to the proponent's simulations that embedded its assumptions about how the hydro-system should operate in the future with and without the cable (Duncan 2008, 2004).

\subsection{A proponent's story of being certain about what was uncertain}

Roe maintains that a narrative analysis should seek to focus attention on how actors are “certain of uncertainty” and how they attempt to persuade others about certainty (Roe 1994: 110). Hence, rather than conduct a critique of a project's technical aspects which can descend into interminable arguments, a narrative analysis draws attention to the interstitial spaces that can be discursively glossed over in the midst of complexity and uncertainty.

It was disclosed during the Basslink public inquiry by the proponent's consultants that when it became evident that the comparison between the baselines resulted in a significant increase in the highest volume power station discharges with Basslink, they started looking much closer at their data (Connarty recorded testimony). Their investigation identified what they believed were anomalies arising from the structure of the model. The way the model was originally designed was to offer all the capacity of the Gordon power station (three turbines at once) into the market at one time. The proponent's consultants came to the conclusion that the model was biased. Given that at this stage of the process it was not possible to develop a new simulation model, the ostensibly flawed model outputs were passed on to external researchers who concluded that Basslink would increase the probability of river bank scour (Koehnken et al. 2001) 
and result in the loss of riparian vegetation in vulnerable zones up to a height of between 4.0-4.5 metres of the riverbank beyond an existing scour zone at 2.5 metres (Davidson and Gibbons 2001a: 11, 2001b: 10) and the loss of macroinvertebrate assemblages (Davies and Cook 2001). To resolve the disparity, statements about environmental impacts throughout the impact assessment statement (IAS) were qualified by a story about a model bias. For example:

The ... model in its present configuration makes offers on a power stationby-power station basis without consideration for use of individual generators ... Output ... is therefore biased (NSR Environmental Consultants Pty Ltd 2001: 12-10).

The proponent's consultants further maintained in the IAS and at the public inquiry that the high level of discharges depicted in the so-called biased model were a worst-case scenario, which was unlikely to eventuate (Connarty 2001a; 2001b; recorded testimony). Crucially, the assessment body adopted the story as its own:

While there is uncertainty as to the actual rate of accelerated present rates of loss of riparian vegetation communities, it is reasonable to assume that these may be less than predicted using the [hydro-system simulation] model, which overestimates full gate discharge (JAP 2002: 345).

\subsection{A compelling story but an unexpected reality check}

After three years of pre- and three years of post-Basslink monitoring, it has been reported by the hydro corporation, under statutory monitoring requirements imposed through the assessment process, that environmental impacts on the Gordon River are occurring beyond the qualified claims settled upon during the assessment process. Increased seepage erosion is resulting in river bank slumping and the loss of riparian vegetation along vulnerable sections of the river banks between the height of 2.5-4.0 metres (HT 2010: 110-111). The proponent concludes:

Over the post-Basslink period, the vegetation monitoring has shown sustained patterns of vegetation stratification in all zones and fluctuations between and within the monitored sites. ... The flow conditions considered 
responsible for the increase in seepage erosion and subsidence which led to the vegetation changes were outside the pre-Basslink range ... this requires an investigation into adaptive management options (HT 2010: 172)

Environmental impacts such as these were predicted, documented and tendered in the IAS and testimony explaining them was presented during the public inquiry.

Notwithstanding, the compelling story told by the proponent's consultants about a model bias convinced the assessment panel to conclude that the environmental impacts were unlikely to be as severe as predicted (JAP 2002).

Roe (1994: 2) maintains that stories are “a force in themselves”, that they can "resist change or modification even in the presence of contradicting empirical data” and that they can "stabilize assumptions for decision making". In my view, these theoretical propositions are useful for understanding the social-interactive role of narratives in a proponent's rendition of uncertainty. In terms of Basslink, in the midst of problematic baselines and data and a model not built for purpose, the proponent's story about what it was certain about - a model bias - served to diminish the veracity and scale of conclusions derived by its external researchers about the potential environmental impacts of Basslink on the Gordon River. The overall outcome of the model bias story was to shift an initial prediction of a 20 per cent increase in full capacity discharges (reported in the impact assessment statement) to an increase that was deemed “negligible” (Bluhdorn 2001: 4) during the public inquiry.

\subsection{What did the story gloss over?}

Of course, the uncertainties and contingencies across aspects of a project such as this are obviously considerable and predictions are all that can be made. However, without adequate disclosure and opportunities for deliberation and negotiation of the numbers 
that drive those predictions, the choices made by proponents and the values they embody lack legitimacy at the outset, even before conclusions are derived. For example, the Basslink modelling embedded the proponent's interpretations of extrapolations of past hydrological variability into the future, assumptions about the capacity of the existing hydro-system, potential future demand in the national and Tasmanian electricity markets and the hydro corporation’s potential future market share (Duncan 2008, 2006, 2004). Stakeholders and publics are well aware of the nature of predictive models even if they do not understand the details. They know that what goes in determines what comes out.

\section{A new approach to grappling with uncertainty}

\subsection{A shift to collaborative knowledge-making}

In light of the challenges of a reliance on disclosure and the social-interactive aspects of the rendition of uncertainty, I now turn to asking what might be some alternative means of grappling with uncertainty in IA? Partidario and Sheate (2012) provide considerable insight into some possibilities. They propose the opening up of institutional spaces in IA that can facilitate power sharing and learning between proponents and stakeholders. They argue that linear models of knowledge transfer (citing Best and Homes 2010; see also Forsyth 2003; Irwin and Wynne 1996; Irwin 2001 for similar perspectives from the field of science studies) are insufficient to deal with the challenges now faced in IA, in particular in respect of Strategic Environmental Assessment (SEA) and Sustainability Assessment (SA).

\subsection{Opportunities for negotiating key model assumptions and parameters}


In practice, what Partidario and Sheate (2012) call knowledge brokerage based on a facilitator/learning school, and what I would call collaborative knowledge-making, would involve proponents and stakeholders deliberating to learn collectively in the process of coproducing knowledge needed to conduct SEA and SA. In my view, Partidario and Sheate (2012) rightly emphasise the necessity of learning and facilitation in collaborative knowledge-making (see also Callon 2001, 1999; Cash 2006;

Wallington et al. 2010). The spaces they envisage could play a potentially crucial role in grappling with uncertainty by facilitating deliberation and negotiation of foundational assumptions and parameters before they become embedded in predictive models and obscured from view. This move would acknowledge that “[k]nowledge and values owned by those other than proponents of projects, plans or policies may be critical in terms of their ability to hold those proponents to account and whether decisions ultimately are seen by others as legitimate” (Partidario and Sheate 2010, np). Hence, the uncertainties and contingencies that can travel so readily through predictive models would be deliberatively negotiated before they are set on their path.

\section{Conclusions}

To conclude, I have argued that the disclosure of uncertainty is necessary but not sufficient. It has been shown that a practitioner's capacity to adequately disclose uncertainty is seriously diminished in light of current epistemic practice that is reliant upon multiple sets of consultants and predictive models. It is doubtful that actors receiving model inputs to create model outputs could possibly assess or appropriately disclose the extent of the uncertainties and contingencies. From this vantage point, the assumption that uncertainties can faithfully be catalogued and disclosed appears somewhat naïve and the practice of disclosure limited to providing less than partial accounts. Revealing the social-interactive aspects of uncertainty with a narrative 
analysis illustrated the extent of the challenge to manage uncertainty with a reliance on disclosure. It has been argued by Partidario and Sheate (2012) that new institutional spaces need to be opened up in IA to facilitate the coproduction of knowledge with a focus on facilitation and learning between stakeholders and proponents. My research on the problematic epistemic implications of current IA practice supports these calls for reform. I have argued here that the opening up of new IA institutional spaces could facilitate the deliberation and negotiation of foundational assumptions that feed into predictive models and learning about the dimensions and implications of the contingencies inherent in any knowledge claims. In my view, this would be a superior approach for seeking to grapple with uncertainty as it has the potential to engender greater legitimacy and credibility for IA outcomes.

\section{REFERENCES}

Bluhdorn D. Gordon River Basslink Monitoring Program and Adaptive Management Plan 2001-2010; 2001. Hobart: Hydro-Electric Corporation.

Burman E and Parker I. Introduction - Discourse analysis: the turn to the text In: Burman E and Parker I, editors; 1993. London: Routledge: 1-13.

Callon M. Acting in an uncertain world: an essay on technical democracy. Cambridge: MIT Press; 2001.

Callon M. The role of lay people in the production and dissemination of scientific knowledge. Science Technology and Society: 1999; 4:81-94.

Cash DW Borck JC and Patt AG. Countering the Loading-Dock Approach to Linking Science and Decision Making: Comparative Analysis of El Nino/Southern Oscillation (ENSO) Forecasting Systems. Sci Technol Hum Val; 2006. 31(4):465-94.

Collins HM. Public Experiments and Displays of Virtuosity: The Core-Set Revisited, Soc Stud Sci 1988;18(4):725-48.

Connarty M. DIIAS Appendix 29: TEMSIM Sensitivity Study on Implications of Basslink. Hobart: Hydro Tasmania; 2001a.

Connarty M. Response to TEMSIM Modelling Issues Arising from the Basslink IIAS. 
Hobart: Hydro-Electric Corporation; 2001b.

Davidson N and Gibbons A. DIIAS Appendix 6: Gordon River Riparian Vegetation Assessment. Hobart: Hydro Tasmania; 2001a.

Davidson N and Gibbons A. Gordon River Riparian Vegetation Assessment Update to IIAS. Hobart: Hydro Tasmania; 2001b.

Davies PD and Cook LSJ. DIIAS Appendix 7: Gordon River Macroinvertebrate and Aquatic Mammal Assessment. Hobart: Hydro Tasmania; 2001.

Duncan R. Science Narratives: the Construction, Mobilisation and Validation of Hydro Tasmania’s Case for Basslink. Ph.D. Thesis. Hobart: University of Tasmania; 2004. http://eprints.utas.edu.au/238/

Duncan R. The Use of Predictive Modelling in Impact Assessment: Implications for Environmental Legislation and Regulation. Aust J Publ Admin 2006; 65(1):75-88.

Duncan R. Problematic practice in integrated impact assessment: the role of consultants and predictive computer models in burying uncertainty. Impact Assessment and Project Appraisal 2008;26(1):53-66.

Forsyth T. Critical political ecology: the politics of environmental science. London: Routledge; 2003: 231-265.

Glasson J, Therivel $\mathrm{R}$ and Chadwick A. Introduction to Environmental Impact Assessment $3^{\text {rd }}$ ed. London: Routledge; 2005: 126-156.

Hajer M. The politics of environmental discourse: ecological modernization and the policy process. Oxford: Oxford University Press; 1995.

Hajer M and Laws D. Ordering through Discourse. In: Moran M, Rein M and Goodin RE, editors. The Oxford Handbook of Public Policy, Oxford University Press, Oxford; 2006. p. 251-68.

Hellstrom T and Jacob M. Uncertainty and values: the case of environmental impact assessment. Knowledge and Policy: The International Journal of Knowledge Transfer and Utilization 1996;9(1): 70-84.

HT (Hydro Tasmania) Basslink Review Report 2006-09: Gordon River Basslink Monitoring Program April 2010. Hydro Tasmania: Hobart; 2010. http://www.hydro.com.au/environment/basslink-studies

Institute of Environmental Management and Assessment. Code of Practice for EIA Practitioners. http://www.iema.net/Accessed 17 May 2012

Irwin A and Wynne B. Introduction in Irwin A and Wynne B (editors)

Misunderstanding Science? The public reconstruction of science and technology. Cambridge: Cambridge University Press; 1996. 
Irwin A. Sociology and the environment: a critical introduction to society, nature and knowledge. Cambridge: Polity Press; 2001.

JAP (Joint Advisory Panel) Final Scope Guidelines. Hobart: Resource Planning and Development Commission; 2000.

JAP (Joint Advisory Panel) Final Panel Report. Hobart: Resource Planning and Development Commission; 2002.

Jasanoff S and Wynne B. Science in decisionmaking In: Rayner S and Malone EL, editors. Human Choice and Climate Change, Volume 1, The Societal Framework. Ohio: Battele Press; 2001:1-87.

Koehnken L, Locher H and Rutherfurd I. DIIAS Appendix 4: Gordon River Fluvial Geomorphology Assessment. Hobart: Hydro Tasmania; 2001.

Lahsen M. Seductive simulations? Uncertainty Distribution around Climate Models, Soc Stud Sci 2005;35(6):895-922.

MacKenzie D. Inventing Accuracy: A Historical Sociology of Nuclear Missile Guidance. Cambridge MA: MIT; 1990.

NSR Environmental Consultants Pty Ltd. Draft Integrated Impact Assessment Statement. Hawthorn East: NSR Environmental Consultants; 2001.

Partidario MR and Sheate WR. Knowledge brokerage - potential for increased capacities and shared power in impact assessment. Environ Impact Asses Rev: 2012, doi: 10.1016/j.eiar.2012.02.002 In press. On line 27 March 2012.

Roe EM. Narrative Policy Analysis: Theory and Practice. Durham: Duke University Press; 1994.

Shackley S and Wynne B. Integrating knowledges for climate change: pyramids, nets and uncertainties. Glob Environ Chang. 1995: 5(2): 113-26.

Vaughan D. The role of the organization in the production of techno-scientific knowledge. Soc Stud Sci 1999;29(6):913-943.

Wallington TB, Maclean K, Darbas T and Robinson CJ. Knowledge-action systems for integrated water management: national and international experiences, and implications for South East Queensland. Urban Water Security Research Alliance Technical Report No. 29. 2010.

Wood A and Kroger O. Doing discourse analysis: methods for studying action in talk and text. Thousand Oaks: Sage Publications; 2000.

Wynne B. Uncertainty and Environmental Learning: Reconceiving Science and Policy in the Preventive Paradigm, Glob Environ Chang. 1992: 111-27. 